\title{
Ventilatory and cerebrovascular responses in normocapnic and hypercapnic COPD patients
}

\author{
M.J.T. Van de Ven*, W.N.J.M. Colier\#, M.C. Van der Sluijs", B.T.P. Kersten*, B. Oeseburg\#, H. \\ Folgering*
}

Ventilatory and cerebrovascular responses in normocapnic and hypercapnic COPD patients. M.J.T. Van de Ven, W.N.J.M. Colier, M.C. Van der Sluijs, B.T.P. Kersten, B. Oeseburg, H. Folgering. (C) ERS Journals Ltd 2001.

ABSTRACT: This study investigated the hypothesis that hypercapnia in some chronic obstructive pulmonary disease (COPD) patients may be related to a high cerebrovascular response to carbon dioxide $\left(\mathrm{CO}_{2}\right)$.

The relationship between responses of ventilation and of cerebral blood volume (CBV) to acute changes in carbon dioxide tension in arterial blood $\left(\mathrm{Pa}, \mathrm{CO}_{2}\right)$ was measured in 17 chronic hypercapnic $\left(\mathrm{Pa}_{\mathrm{a}}, \mathrm{CO}_{2}>6.0 \mathrm{kPa}\right)$ and 16 normocapnic $\left(\mathrm{P}_{\mathrm{a}}, \mathrm{CO}_{2}\right.$ $\leqslant 6.0 \mathrm{kPa}$ ) COPD patients, who were matched for degree of airway obstruction (forced expiratory volume in one second $27 \%$ predicted). Results were compared with 15 agematched healthy subjects. CBV was measered using near infrared spectroscopy during normo- and hypercapnia and related to inspired minute ventilation $\left(V^{\prime} I\right)$ and mouth occlusion pressure $\left(P_{0.1}\right)$. Hypercapnia (end-tidal pressure of carbon dioxide $\left.\left(\triangle P E T, \mathrm{CO}_{2}\right)>1 \mathrm{kPa}\right)$ was induced by giving adequate amounts of $\mathrm{CO}_{2}$ in the inspired air.

During normocapnia, CBV $\left(\mathrm{mL} \cdot 100 \mathrm{~g}^{-1}\right)$ was $2.41 \pm 0.66$ and $2.90 \pm 0.60$ (mean \pm SD) in the normocapnic and chronic hypercapnic patients, respectively, which was significantly lower compared to healthy subjects $(3.53 \pm 0.77)$. All slopes of $\mathrm{CO}_{2}$ responsiveness $\left(\Delta \mathrm{CBV} I \Delta \mathrm{P}_{\mathrm{a}}, \mathrm{CO}_{2}, \Delta V^{\prime} \mathrm{I} / \Delta \mathrm{P}_{\mathrm{a}}, \mathrm{CO}_{2}, \Delta \mathrm{P}_{0.1} / \Delta \mathrm{P}_{\mathrm{a}}, \mathrm{CO}_{2}\right)$ were significantly lower in both COPD groups relative to healthy subjects, but were not significantly different between the COPD groups. $A$ poor but positive correlation between ventilatory and cerebrovascular $\mathrm{CO}_{2}$ responsiveness $\left(\Delta \mathrm{CBV} I \Delta P \mathrm{a}, \mathrm{CO}_{2}\right.$ and $\left.\Delta V^{\prime} \mathrm{I} / \Delta P \mathrm{a}, \mathrm{CO}_{2}\right)$ was found in COPD patients and healthy subjects.

The findings do not support the hypothesis of abnormal cerebrovascular responses to carbon dioxide in hypercapnic chronic obstructive pulmonary disease patients. Eur Respir J 2001; 18: 61-68.

\begin{abstract}
*Dept of Pulmonology Dekkerswald, University of Nijmegen, Groesbeek, and ${ }^{\#}$ Dept of Physiology, Faculty of Medical Sciences, University of Nijmegen, Nijmegen, The Netherlands.
\end{abstract}

Correspondence: M.J.T. Van de Ven, Dept of Pulmonology Dekkerswald, University of Nijmegen, PO Box 9001, 6560 GB Groesbeek, The Netherlands. Fax: 31246859290

Keywords: Cerebral blood volume chemoresponsiveness

chronic obstructive pulmonary disease control of breathing

mouth occlusion pressure

near infrared spectroscopy

Received: October 62000

Accepted after revision February 15 2001

This study was supported by the Dutch Asthma Foundation (96.09).
Patients with chronic obstructive pulmonary disease (COPD) frequently show a blunted ventilatory response to hypercapnia. This diminished response has been ascribed to either mechanical limitations imposed by the disease process itself ("can't breathe") or to reduced sensitivity of the respiratory centres to the carbon dioxide $\left(\mathrm{CO}_{2}\right)$ stimulus ("won't breathe") [1]. Both will result in $\mathrm{CO}_{2}$ retention and hypercapnia. Furthermore, the carbon dioxide tension in arterial blood $\left(P a, C_{2}\right)$ values are often used as the input parameter for measuring ventilatory responsiveness. As the central chemoreceptors represent $\sim 80 \%$ of the total $\mathrm{CO}_{2}$ chemosensitivity [2], it might be conceived that the stimulus to these central chemoreceptors, brain interstitial fluid (ISF)-pH, is neither adequately processed, nor adequately reflected by the $\mathrm{Pa}_{\mathrm{a}} \mathrm{CO}_{2}$ value in the hypercapnic COPD patients. The latter may occur when the control of cerebral blood flow $(\mathrm{CBF})$ and cerebral blood volume (CBV) and their reponses to changes in $P \mathrm{a}, \mathrm{CO}_{2}$ are abnormal.

The importance of $\mathrm{CBF}$ as a crucial link in stimulus-response studies of ventilatory control was first pointed out by the classical study of KETY and SchmidT [3]. Since then, CBF was thought to modify the apparent ventilatory responses to changes in $\mathrm{Pa}_{\mathrm{a}} \mathrm{CO}_{2}$. Variations in blood flow will alter the relationship between $\mathrm{Pa}, \mathrm{CO}_{2}$ (the stimulus that can be measured) and the $\mathrm{CO}_{2}$ tension of brain tissue at the central chemoreceptors (the true stimulus). Simultaneous measurements of cerebrovascular and of ventilatory reactivity are therefore important [4].

As reviewed by Feinl and Perret [5], both cerebral resistance vessels (arterioles) and capillaries/venules are dilated by hypercapnia. However, a chronic hypercapnia is associated with a blunted cerebrovascular reactivity to acute $P \mathrm{a}, \mathrm{CO}_{2}$ variations [6]. As a result, only minor alterations in CBF and CBV can be expected, not able to attenuate the acute hypercapnic stimulus to the central chemoreceptors, and leading to an elevated $P \mathrm{a}, \mathrm{CO}_{2}$ in the ISF (true stimulus). Consequently, an elevated ventilatory drive could be expected. However, the opposite, a lowered ventilatory drive is found $[7,8]$.

According to PonTÉn and SIeSJö [9] and others [4], a 
high $\mathrm{CBF}$ (and $\mathrm{CBV}$ ) washes out tissue $\mathrm{CO}_{2}$ and lowers $\mathrm{Pa}, \mathrm{CO}_{2}$ in the ISF, leading to a low chemoreceptor stimulus and a low ventilatory drive. An inverse relationship between cerebrovascular and ventilatory responsiveness to acute hypercapnia in COPD patients was hypothesized. Relatively high vasodilatating cerebrovascular responses were hypothesized in hypercapnic patients, leading to a wash-out from $\mathrm{CO}_{2}$ and a lowered $\mathrm{Pa}_{2} \mathrm{CO}_{2}$ in the ISF. This would result in a low chemoreceptor stimulus and a low ventilatory drive and sustained systemic hypercapnia. Normocapnic patients, however, may be thought to show a lowered cerebrovascular response and thus an adequate ventilatory drive, leading to systemic normocapnia.

In the present study, cerebrovascular $\mathrm{CO}_{2}$ responsiveness was expressed as the slope of $\mathrm{CBV} / \mathrm{CO}_{2}$ plot $\left(\triangle \mathrm{CBV} / \triangle \mathrm{Pa}, \mathrm{CO}_{2}\right)$ and ventilatory $\mathrm{CO}_{2}$ responsiveness was expressed as the slope of inspired minute ventilation $\left(V^{\prime} \mathrm{I}\right) / \mathrm{CO}_{2}\left(\Delta V^{\prime} \mathrm{I} / \Delta P \mathrm{a}, \mathrm{CO}_{2}\right)$. CBV was measured using a noninvasive technique of near-infrared spectroscopy (NIRS). Mouth occlusion pressure $\left(P_{0.1}\right)$ and its response to changes in $P \mathrm{a}, \mathrm{CO}_{2}\left(\Delta P 0.1 / \Delta P \mathrm{a}, \mathrm{CO}_{2}\right)$ were measured in order to approximate the ventilatory drive independent of airway resistance.

\section{Materials and methods}

\section{Subjects}

The study was performed on 33 patients with COPD as defined by the American Thoracic Society. Ten males and six females, aged (mean \pm SD) $60 \pm$ $11 \mathrm{yrs}$, were normocapnic $\left(\mathrm{Pa}, \mathrm{CO}_{2} \leqslant 6.0 \mathrm{kPa}\right)$ and $\overline{15}$ males and two females, aged $63 \pm 8$ yrs were hypercapnic $\left(\mathrm{Pa}, \mathrm{CO}_{2}>6.0 \mathrm{kPa}\right)$. Patients were excluded if they: 1) had evidence of obstructive sleep disorders or restrictive pulmonary function; 2) had an exacerbation in the 6 weeks before enrollment; 3 ) had a history of cardiopulmonary, cerebrovascular or other chronic diseases; and 4) took medications other than pulmonary bronchodilating agents, theophyllines and (systemic) corticosteriods. Three normocapnic and two hypercapnic patients were current smokers, all other patients stopped smoking for $>6$ months. An age-matched healthy control group $(56 \pm 10 \mathrm{yrs}$, six males, 10 females) was also studied. None of them were on medication. A description of the patients is presented in table 1.

At least $2 \mathrm{~h}$ prior to the experiments, all participants were asked to abstain from caffeinated drinks and cigarettes, but were allowed to continue their pulmonary medication. All volunteers gave informed consent. The study was approved by the ethical committee of the Department of Pulmonology Dekkerswald, University of Nijmegen.

\section{Measurements}

Ventilation measurements. The subjects were in a comfortable, reclining position. They were breathing through a face mask with low-resistance valves for inspiratory and expiratory gas mixture. First, dead space ventilation $(V \mathrm{D} / V \mathrm{~T})$ was measured using the Bohr equation. Expiratory air was collected in a Douglas bag for $10 \mathrm{~min}$ for measurements of expiratory $\mathrm{PCO}_{2}$ (capnograph N1000, Nellcor Puritan Bennet, MO, USA). Next, the inspiratory port of the mask was connected via a Fleisch pneumotachograph (Phipps \& Bird, Richmond, VA, USA) to an inspiratory reservoir (fig. 1). The flow signal was integrated into $V^{\prime} \mathrm{I}$. Air was sampled from the expiratory port of the mask to a capnograph to monitor end-tidal $\mathrm{CO}_{2}\left(P \mathrm{ET}, \mathrm{CO}_{2}, \mathrm{kPa}\right)$ and respiratory rate $\left(\mathrm{RR}, \mathrm{min}^{-1}\right)$. Changes in inspiratory gas mixture of oxygen $\left(\mathrm{O}_{2}\right)$, nitrogen $\left(\mathrm{N}_{2}\right)$ and $\mathrm{CO}_{2}$ were induced by means of a computer-controlled mass flow system (Bronckhorst, Hitec, Veenendaal, the Netherlands). The fraction of inspired $\mathrm{O}_{2}\left(F \mathrm{I}, \mathrm{O}_{2}\right)$ was monitored continuously using an oxygen analyser (OM-11, Beckman Inc., CA, USA). Fast changes in the inspiratory gas mixture could be induced; the aimed changes were reached within one breath. Hypercapnia $\left(\triangle P\right.$ ET, $\left.\mathrm{CO}_{2}>1 \mathrm{kPa}\right)$ was induced by giving adequate amounts of $\mathrm{CO}_{2}\left(F \mathrm{I}, \mathrm{CO}_{2} 3-5 \%\right)$ in the inspired air.

Table 1.-Characteristics of normocapnic patients, chronic hypercapnic patients and control subjects

\begin{tabular}{lccc}
\hline Variable & Normocapnic COPD & Hypercapnic COPD & Controls $^{+}$ \\
\hline Age yr & $59.8 \pm 10.7$ & $62.8 \pm 8.4^{*}$ & $56 \pm 1$ \\
$\mathrm{BMI} \mathrm{kg} \cdot \mathrm{m}^{-2}$ & $22.9 \pm 2.54$ & $21.5 \pm 2.4^{* *}$ & $24.2 \pm 3.1$ \\
$\mathrm{FEV} \%$ pred & $28.8 \pm 9.6^{* * *}$ & $24.3 \pm 7.5^{* * *}$ & $88.7 \pm 8.8$ \\
$\mathrm{MIP} \%$ pred & $87.9 \pm 39.9$ & $77.2 \pm 29.8$ & \\
$\mathrm{MEP} \%$ pred & $69.6 \pm 28.7$ & $59.4 \pm 25.7$ & \\
$V \mathrm{D} / \mathrm{T} \%$ & $48 \pm 11$ & $53 \pm 7$ & $40.8 \pm 3.1$ \\
$\mathrm{Ht} \mathrm{vol} \%$ & $41.6 \pm 3.6$ & $42.0 \pm 3.4$ & $5.14 \pm 0.36$ \\
$P \mathrm{a}, \mathrm{CO}_{2} \mathrm{kPa}$ & $5.26 \pm 0.27$ & $8.31 \pm 0.45^{* * *}$ & \\
$\mathrm{PaO}_{2} \mathrm{kPa}$ & $9.05 \pm 0.59$ & $7.39 \pm 0.09^{* *}$ & $7.45 \pm 0.03$ \\
$\mathrm{pH}$ & $7.42 \pm 0.02^{* * *}$ & $28.0 \pm 1.6^{* *}$ & $25.6 \pm 1.8$ \\
$\mathrm{HCO}{ }_{3}^{-} \mathrm{mEq} \cdot \mathrm{L}^{-1}$ & $25.2 \pm 1.2$ & $2.4 \pm 1.3^{* *}$ & $2.1 \pm 1.7$ \\
$\mathrm{BE} \mathrm{mEq} \cdot \mathrm{L}^{-1}$ & $0.8 \pm 1.2^{* * *}$ & & \\
\hline
\end{tabular}

Data are presented as mean \pm SD. COPD: chronic obstructive pulmonary disease; BMI: body mass index; MIP: maximal inspiratory pressure; MEP: maximal expiratory pressure; $\mathrm{Ht}$ : haematocrit; $\mathrm{BE}$ : base excess; FEV1: forced expiratory volume in one second; $V \mathrm{D}$ : dead space volume; $V$ T: tidal volume; $P$ a, $\mathrm{CO}_{2}$ : carbon dioxide tension in arterial blood; $P$ a, $\mathrm{O}_{2}$ : oxygen tension in arterial blood; $\mathrm{HCO}_{3}{ }^{-}$: bicarbonate. $*: \mathrm{p}<0.05 ; * * \mathrm{p}<0.01 ; * *: \mathrm{p}<0.001, \mathrm{COPD}$ group compared to control group; ${ }^{+}$control group: arterialized capillary blood gas sampling (control group of arterialization capillary blood gas sampling). 


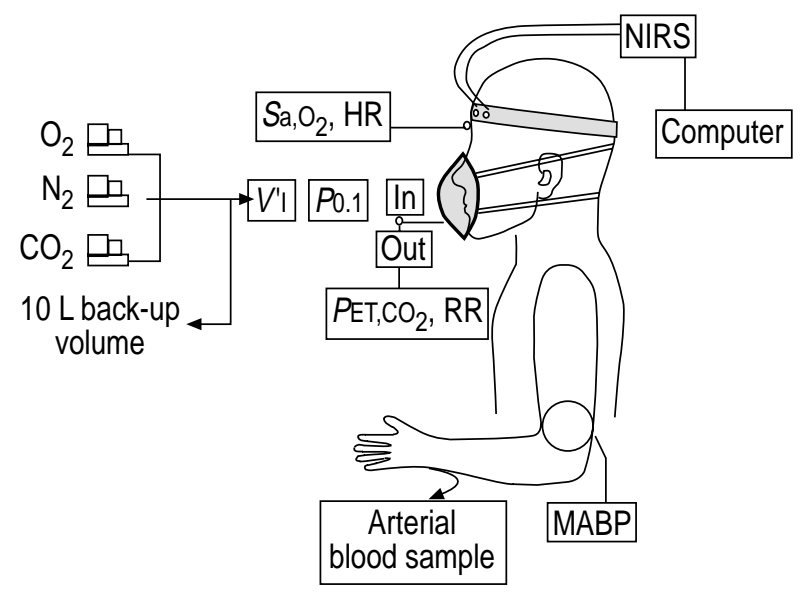

Fig. 1. - Experimental set-up. Flow of oxygen $\left(\mathrm{O}_{2}\right)$, nitrogen $\left(\mathrm{N}_{2}\right)$, and carbon dioxide $\left(\mathrm{CO}_{2}\right)$ are regulated with a mass-flow controller. Arterial oxygen saturation $\left(\mathrm{Sa}_{\mathrm{a}} \mathrm{O}_{2}\right)$ and heart rate $(\mathrm{HR})$ are measured with pulse-oximetry. NIRS: near-infrared spectroscopy; $V^{\prime}$ I: inspired minute ventilation, measured by pneumotachography; $P_{0.1}$ : mouth occlusion pressure; MABP: mean arterial blood pressure; $P$ ET, $\mathrm{CO}_{2}$ and RR: end-tidal $\mathrm{CO}_{2}$ and respiratory rate measured by capnograph. For safety reasons, a back-up volume of $10 \mathrm{~L}$ was created. Arterial blood was sampled from the left brachial artery.

Cerebral blood volume measurements. NIRS has been developed to monitor brain oxygenation and dynamics [10]. The theory of NIRS has been described extensively [11]. The technique is based on oxygenationdependent absorption changes in the blood caused by chromophores, mainly oxy- and deoxyhaemoglobin $\left(\left[\mathrm{O}_{2} \mathrm{Hb}\right]\right.$ and $[\mathrm{HHb}]$, respectively). Near-infrared light was carried to and from a pulsed continuous-wave NIRS instrument (Oxymon, Depts of Physiology and Instrumentation, University of Nijmegen, the Netherlands) through two fibreoptic bundles (optodes) on the left side of the forehead. One optode emits nearinfrared light at three different wavelengths, which penetrates through the skull/brain. The receiving optode is positioned at a distance of $5.5 \mathrm{~cm}$ apart from the emitting optode. This distance ensures that most of the extacranial circulation is excluded from the detected signal [12].

Calculation of CBV was described by Elwell et al. [13]. A slight change of saturation $(\sim 5 \%)$ is necessary to quantify $\mathrm{CBV}$. The change of saturation is related to the difference in concentration of haemoglobin chromophores at two levels of saturation. CBV can be calculated taking the individual haemoglobin concentration into account and a fixed constant. The constant accounts for molecular weight of haemoglobin, cerebral tissue density and the cerebral-to-large vessel haematocrit ratio.

Mouth occlusion pressure measurements. Ventilatory effort during inspiration was determined by $P 0.1$ after the start of inspiration. A solenoid valve was positioned in the inspiratory line of the circuit [14]. Closure of the valve during expiration was manually controlled, and the valve automatically opened after the first $100 \mathrm{~ms}$ of the occluded inspiration. Five repeated measurements of $P_{0.1}$ were averaged during each $\mathrm{CO}_{2}$ condition. $P 0.1$ was expresssd both as absolute value $\left(\mathrm{cmH}_{2} \mathrm{O}\right)$ and as percentage of maximal inspiratory pressure (MIP), in order to normalize $P_{0.1}$ for the individual differences in inspiratory muscle strength [15].

\section{Protocol}

All patients underwent routine spirometry and blood analysis of haemoglobin, haematocrit and resting arterial blood gases to assign the individual patients into the normocapnic and chronic hypercapnic COPD group. A canula was introduced in the left brachial artery to collect arterial blood samples. Arterial oxygen saturation $\left(\mathrm{S}_{\mathrm{a}}, \mathrm{O}_{2}\right)$ and heart rate $(\mathrm{HR})$ were monitored with a pulse-oximeter (N200; Nellcor Puritan Bennet, MO, USA), with the sensor attached to the right-frontal forehead (fig. 1).

Hypercapnia was induced by giving adequate amounts of $\mathrm{CO}_{2}$ in the inspired air. Duplicate measurements of $\mathrm{CBV}$ and $P_{0.1}$ during normo- and hypercapnia were performed after a period of 10-min equilibration. Arterial pressure was measured manually during each $\mathrm{CO}_{2}$ condition. Mean arterial blood pressure (MABP) was calculated as: diastolic pressure $+1 / 3 \times($ systolic-diastolic) pressure. All data (except MABP) were linked directly to the NIRS computer for real time display and simultaneous storage with the NIRS data.

\section{Statistics}

During the whole experiment, time-averaged values of $V^{\prime} \mathrm{I}, P \mathrm{ET}, \mathrm{CO}_{2}, \mathrm{Sa}_{\mathrm{a}} \mathrm{O}_{2}, \mathrm{HR}$ and RR were recorded, expressed as mean \pm SD during each $\mathrm{CO}_{2}$ challenge. Anthropometric characteristics, pulmonary function, MABP and arterial blood gas values were compared between the three groups by the Mann-Whitney U-test for two independent samples. Within the groups, values during normocapnia were compared to values during hypercapnia using a paired t-test. Between the groups, unpaired t-tests were used to compare outcome variables. For each individual, $\mathrm{CBV}, V^{\prime} \mathrm{I}$ and $P 0.1$ was plotted against corresponding $P a, C_{2}$ values and subjected to linear regression analysis. The individual slopes of $\mathrm{CBV}, V^{\prime} \mathrm{I}$ and $P_{0.1}$ responses to acute $\mathrm{CO}_{2}$ changes were calculated using linear regression analysis. Mean slopes of the three groups were compared with an unpaired test. The level of statistical significance was set at $p<0.05$. All tests should be regarded as explorative due to the multiplicity of tests.

\section{Results}

The anthropometric characteristics and respiratory function data of the patients are summarized in table 1. Both COPD groups showed the same degree of airway obstruction (forced expiratory volume in one second (FEV1)), maximal voluntary ventilation (MVV) and MIP. Acute hypercapnia was attained by 
Table 2.-Outcome parameters before (start) and during hypercapnia when taking carbon dioxide responses in normocapnic patients, chronic hypercapnic patients and control subjects

\begin{tabular}{|c|c|c|c|c|c|c|}
\hline \multirow[t]{2}{*}{ Variable } & \multicolumn{2}{|c|}{ Normocapnic COPD } & \multicolumn{2}{|c|}{ Hypercapnic COPD } & \multicolumn{2}{|c|}{ Controls } \\
\hline & Start & Hypercapnia & Start & Hypercapnia & Start & Hypercapnia \\
\hline $\mathrm{CBV} \mathrm{mL} \cdot 100 \mathrm{~g}^{-1}$ & $2.41 \pm 0.66^{* * *}$ & $3.36 \pm 0.75^{(* * *)}$ & $2.90 \pm 0.60^{[* * *]}$ & $3.76 \pm 0.71^{(* * *)}$ & $3.53 \pm 0.77$ & $4.82 \pm 1.12$ \\
\hline$V^{\prime} \mathrm{I} L \cdot \min ^{-1}$ & $9.7 \pm 2.5^{* *}$ & $16.6 \pm 4.2^{(* * *)}$ & $9.0 \pm 2.0^{*}$ & $12.5 \pm 2.2^{(* * *)}$ & $7.7 \pm 1.4$ & $15.9 \pm 8.3^{(* * *)}$ \\
\hline$P 0.1 \mathrm{cmH}_{2} \mathrm{O}$ & $5.12 \pm 2.57$ & $7.14 \pm 3.44(* * *)$ & $5.31 \pm 2.89$ & $6.76 \pm 3.78^{(* * *)}$ & & \\
\hline$P 0.1 \mathrm{MIP} \%$ & $7.72 \pm 4.53$ & $11.42 \pm 7.19^{(*)}$ & $8.14 \pm 4.38$ & $10.44 \pm 5.17(* *)$ & & \\
\hline$P \mathrm{a}, \mathrm{CO}_{2} \mathrm{kPa}$ & $5.26 \pm 0.27$ & $6.08 \pm 0.24^{(* * *)}$ & $6.27 \pm 0.45^{* *}$ & $6.92 \pm 0.39^{(* * *)}$ & $5.14 \pm 0.36$ & $5.63 \pm 0.29^{(* * *)}$ \\
\hline$P \mathrm{a}, \mathrm{O}_{2} \mathrm{kPa}$ & $9.05 \pm 0.59$ & $10.16 \pm 1.36^{(* *)}$ & $8.31 \pm 0.99$ & $8.94 \pm 0.81^{(* *)}$ & & \\
\hline MVV \% pred & $33.1 \pm 12.7$ & $55.0 \pm 16.7$ & $33.3 \pm 10.2$ & $45.6 \pm 11.9$ & & \\
\hline $\mathrm{RR} \min ^{-1}$ & $16 \pm 4$ & $19 \pm 4(* *)$ & $19 \pm 5^{*}$ & $19 \pm 4$ & $14+3$ & $15+4$ \\
\hline$V \mathrm{~T} \mathrm{~mL}$ & $640 \pm 210$ & $920 \pm 225^{(* * *)}$ & $520 \pm 200$ & $710 \pm 200^{(* * *)}$ & $610 \pm 200$ & $1130 \pm 20^{(* * *)}$ \\
\hline $\mathrm{HR} \min ^{-1}$ & $83 \pm 11 * *$ & $79 \pm 19$ & $82 \pm 12 * *$ & $83 \pm 12$ & $72 \pm 10$ & $71 \pm 10$ \\
\hline MABP mmHg & $106 \pm 12^{* * *}$ & $108 \pm 18$ & $111 \pm 14^{* * *}$ & $110 \pm 13$ & $85 \pm 11$ & $93 \pm 12^{(* * *)}$ \\
\hline
\end{tabular}

Data are presented as mean $\pm \mathrm{SD}$. CBV: cerebral blood volume; $V^{\prime} \mathrm{I}$ : inspired ventilation; $P 0.1$ : mouth occlusion pressure; MIP: maximal inspiratory pressure; MVV: maximal voluntary ventilation; RR: respiratory rate; $V \mathrm{~T}$ : tidal volume; HR: heart rate; MABP: mean arterial blood pressure; $\mathrm{Pa}_{\mathrm{a}} \mathrm{O}_{2}$ : oxygen tension in arteiral blood; $\mathrm{Pa}_{\mathrm{a}} \mathrm{CO}_{2}$ : carbon dioxide tension in arterial blood; $*: \mathrm{p}<0.05 ; * *: \mathrm{p}<0.01 ; * * *: \mathrm{p}<0.001$, COPD group compared to control group (normocapnia compared to acutely induced within the group) [normocapnic COPD group compared to hypercapnia COPD group].

means of a $\Delta P \mathrm{a}_{1} \mathrm{CO}_{2}$ of $0.83 \pm 0.19,0.65 \pm 0.18$ and $0.52 \pm 0.27 \mathrm{kPa}$ in the normocapnic, chronic hypercapnic and healthy (control) group, respectively. The degree of (necessary) transient desaturation to measure absolute values of CBV was $6 \pm 2,7 \pm 2$ and $8 \pm 2 \%$ for the same groups.

Hypercapnia induced significant changes $(\mathrm{p}<0.01)$ in all variables except for HR, RR and MABP, within the three groups (table 2 ). In addition, only normocapnic COPD patients showed a different RR during hypercapnia $(\mathrm{p}<0.01)$, compared to the other two groups. MABP was significantly higher in COPD patients compared to healthy subjects $(\mathrm{p}<0.001)$, but did not increase further during hypercapnia. In healthy subjects, MABP increased during induction of hypercapnia $(\mathrm{p}<0.001)$.

\section{Ventilation and ventilatory responses}

Both COPD groups had significantly higher resting values of $V^{\prime}$ I compared to healthy subjects (table 2 ). The ventilatory response to $\mathrm{CO}_{2}\left(\Delta V^{\prime} \mathrm{I} / \Delta P \mathrm{a}, \mathrm{CO}_{2}\right)$ was lower in both COPD groups when compared to the controls, but was only significantly different $(p<0.01)$ in the hypercapnic group compared to controls (table 3 ). When both COPD groups were compared and the median rather than the average value of $\Delta V^{\prime} \mathrm{I} /$ $\Delta P \mathrm{a}, \mathrm{CO}_{2}$ was taken, a significant, different slope of $\Delta V^{\prime} \mathrm{I} / \Delta P \mathrm{a}, \mathrm{CO}_{2}$ between the two COPD groups was found $(\mathrm{p}<0.05)$. Average responses $\left(V^{\prime} \mathrm{I}: \mathrm{L} \cdot \mathrm{min}^{-1}\right.$; $\left.P \mathrm{a}, \mathrm{CO}_{2}: \mathrm{kPa}\right)$ are displayed in figure $2 \mathrm{~b}$.

In contrast to COPD patients, $V^{\prime} I$ is a good parameter for neuromuscular output of ventilatory drive in healthy subjects. Both absolute values of $P_{0.1}$ (table 2) and its reactivity $\left(\Delta P_{0} .1 / \Delta P \mathrm{a}, \mathrm{CO}_{2}\right.$, table 3$)$ were not significantly different between the COPD groups, even after correction for MIP.

\section{Cerebral blood volume and cerebrovascular responses}

Twelve out of 192 measurements were rejected and excluded from the CBV calculations because of inadequate measurements. Values of $\mathrm{CBV}$ were lower in the normocapnic patients as compared to the hypercapnic patients $(\mathrm{p}<0.01)$ (table 2$)$. Both COPD groups showed a significant, lower value of CBV compared to the healthy subjects. The cerebrovascular response to $\mathrm{CO}_{2}, \Delta \mathrm{CBV} / \Delta P \mathrm{a}, \mathrm{CO}_{2}$, was lower in both COPD groups compared to controls, however, this was only significantly lower $(p<0.05)$ in the hypercapnic group (table 3 ). Average equations of $\mathrm{CBV}$ as a function of $\mathrm{Pa}, \mathrm{CO}_{2}$ are displayed in figure 2 .

Table 3. - Linear regression of cerebral blood volume (CBV), minute ventilation $\left(V^{\prime} I\right)$ and mouth occlusion pressure $\left(P_{0.1)}\right.$ to hypercapnia in normocapnic patients, chronic hypercapnic patients and control subjects

\begin{tabular}{|c|c|c|c|c|c|c|c|c|c|}
\hline \multirow[t]{2}{*}{ Variables } & \multicolumn{3}{|c|}{ Normocapnic COPD } & \multicolumn{3}{|c|}{ Hypercapnic COPD } & \multicolumn{3}{|c|}{ Controls } \\
\hline & Slope & $y$-intercept & $\mathrm{r}$ & Slope & $y$-intercept & $\mathrm{r}$ & Slope & $y$-intercept & $\mathrm{r}$ \\
\hline $\mathrm{CBV} P \mathrm{a}, \mathrm{CO}_{2} \mathrm{~mL} \cdot 100 \mathrm{~g}^{-1} \cdot \mathrm{kPa}^{-1}$ & $1.59 \pm 0.91$ & $-5.18 \pm 5.27$ & 0.9 & $1.23 \pm 0.67 *$ & $-5.16 \pm 3.56$ & 0.77 & $2.10 \pm$ & -7.02 & 0.66 \\
\hline$V^{\prime}$ I $P \mathrm{a}, \mathrm{CO}_{2} \mathrm{~L} \cdot \mathrm{min}^{-1} \cdot \mathrm{kPa}^{-1}$ & $8.2 \pm 4.9^{*}$ & $-33.4 \pm 26.2^{*}$ & 0.96 & $5.5 \pm 4.4^{* * *}$ & $-26.7 \pm 34.3^{* *}$ & 0.93 & $13.9 \pm 7.1$ & $-62.9 \pm 36.8$ & 0.85 \\
\hline$P 0.1 P \mathrm{a}, \mathrm{CO}_{2} \mathrm{cmH}_{2} \mathrm{O} \cdot \mathrm{kPa}^{-1}$ & $2.65 \pm 1.84$ & $-8.67 \pm 9.3$ & 0.81 & $2.83 \pm 1.50$ & $-12.38 \pm 9.18$ & 0.80 & & & \\
\hline
\end{tabular}

Data are presented as mean $\pm \mathrm{SD}$. $\mathrm{Pa}_{2} \mathrm{CO}_{2}$ : carbon dioxide tension in arterial blood; COPD: chronic obstructive pulmonary disease. ${ }^{*}: \mathrm{p}<0.05 ; * * \mathrm{p}<0.01 ;{ }^{* *}: \mathrm{p}<0.001, \mathrm{COPD}$-group compared to control group. $\mathrm{y}$-intercept: $\mathrm{CBV}, V^{\prime}$ I and $P_{0.1}$ value at a $P \mathrm{a}, \mathrm{CO}_{2}$ of $0 \mathrm{kPa}$. 

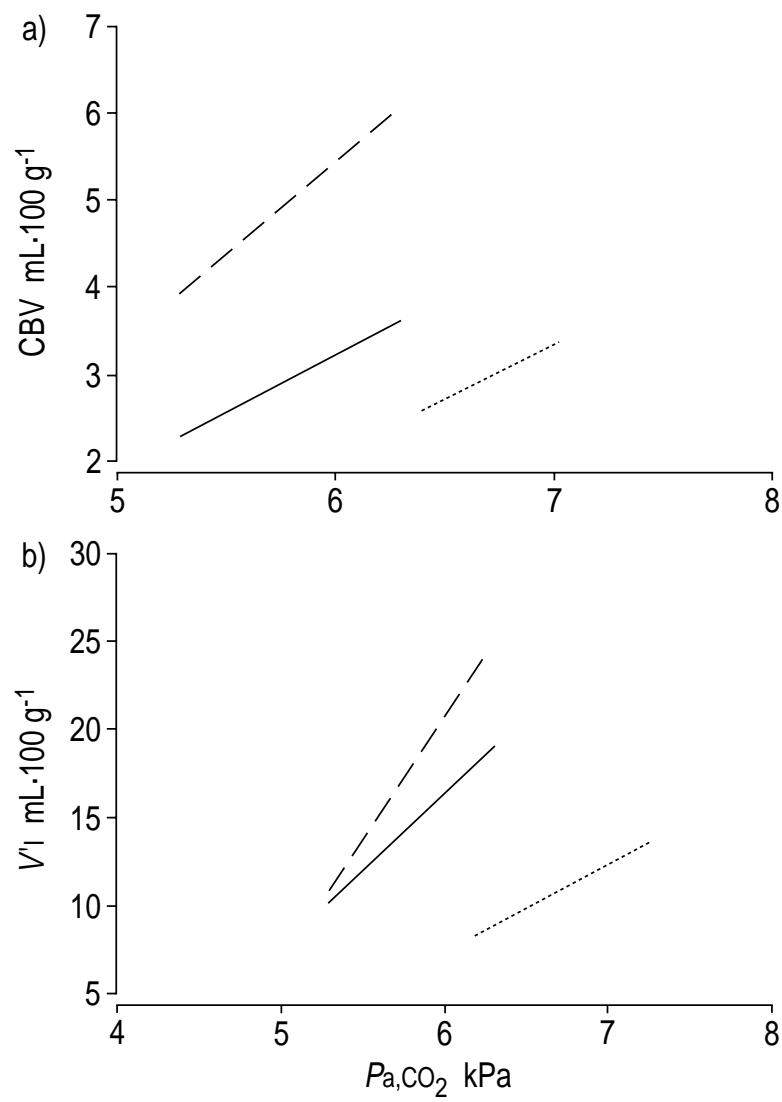

Fig. 2. - Ventilatory and cerebrovascular responses to carbon dioxide. Regression equations were obtained for data from each individual subject and averaged for the group. All values of a) cerebral blood volume $(\mathrm{CBV})$ and $\mathrm{b})$ inspired minute ventilation $\left(V^{\prime} \mathrm{I}\right)$ were indexed to similar carbon dioxide tension in arterial blood $\left(P_{\left.\mathrm{a}, \mathrm{CO}_{2}\right)}\right.$ values to show average group results. --- : controls; - : normocapnic chronic obstructive pulmonary disease; - - - -: hypercapnic chronic obstructive pulmonary disease.

\section{Correlation between the different outcome parameters}

A poor correlation was seen in the control group between the individual $\mathrm{CBV}$ and $V^{\prime} \mathrm{I}$ responses to acute hypercapnia $\left(\Delta \mathrm{CBV} / \Delta P \mathrm{a}, \mathrm{CO}_{2}\right.$ and $\Delta V^{\prime} \mathrm{I} /$ $\left.\triangle P \mathrm{a}, \mathrm{CO}_{2}\right)$. A low, but significant correlation was found for all COPD patients (fig. 3). When the COPD group was subdivided, the normocapnic patients tended to show a steeper slope $\left(\Delta V^{\prime} \mathrm{I} / \Delta P \mathrm{a}, \mathrm{CO}_{2} /\right.$ $\left.\Delta \mathrm{CBV} / \Delta P \mathrm{P}, \mathrm{CO}_{2}\right)$ as compared to the hypercapnic patients (fig. 4). However, the latter correlations were poor and not significant. In addition, when $V^{\prime} \mathrm{I}$ was related to $\mathrm{MVV} \%$ and $V^{\prime}$ I $(\mathrm{MVV} \%) / \Delta P \mathrm{a}, \mathrm{CO}_{2}$ was correlated to $\Delta \mathrm{CBV} / \Delta P \mathrm{a}, \mathrm{CO}_{2}$ (not displayed), correlations remained poor. Nevertheless, the slope of these correlations was positive, showing that high cerebrovascular responses were accompanied by high ventilatory responses to $\mathrm{CO}_{2}$.

Correlations between the individual $\mathrm{CBV}$ and $P_{0.1}$ slopes $\left(\Delta \mathrm{CBV} / \Delta P \mathrm{a}, \mathrm{CO}_{2}\right.$ and $\left.\Delta P 0.1 / \Delta P \mathrm{a}, \mathrm{CO}_{2}\right)$ were poor and not significant in both COPD groups $(\mathrm{r}=0.28$ and 0.04 in the normocapnic and hypercapnic COPD group, respectively). In order to evaluate CBV with respect to parasympathetic tone, $\mathrm{CBV}$ and $\mathrm{HR}$ were
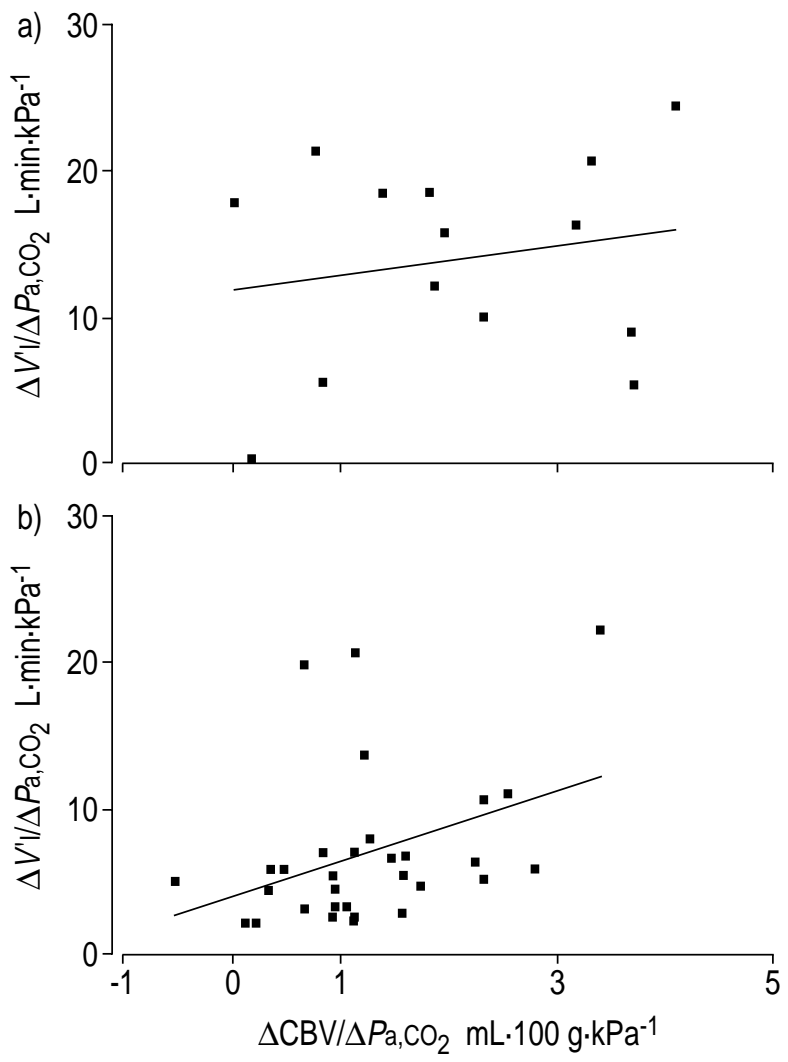

Fig. 3. - Correlation between ventilatory and cerebrovascular carbon dioxide $\left(\mathrm{CO}_{2}\right)$-responsiveness in healthy subjects (control) and chronic obstructive pulmonary disease (COPD) patients. The relationship between a) the individual ventilatory/ $\mathrm{CO}_{2}$ tension in arterial blood $\left(\Delta V^{\prime} \mathrm{I} / \Delta P \mathrm{a}, \mathrm{CO}_{2}\right)$ and cerebrovascular $\left(\Delta \mathrm{CBV} / \Delta P \mathrm{a}, \mathrm{CO}_{2}\right)$ $\mathrm{CO}_{2}$-responsiveness in healthy subjects and b) in normo- and hypercapnic COPD patients. The regression equation, describing the inter-individual relationship between a) $V^{\prime} \mathrm{I} / \Delta P \mathrm{a}, \mathrm{CO}_{2}$ and $\Delta \mathrm{CBV} / \Delta P \mathrm{a}_{1} \mathrm{CO}_{2}$ is $\Delta V^{\prime} \mathrm{I} / \Delta P \mathrm{a}_{1} \mathrm{CO}_{2}=0.99 \times \Delta \mathrm{CBV} / \Delta P \mathrm{a}_{1} \mathrm{CO}_{2}+11.80$ $(\mathrm{r}=0.2 ; \mathrm{p}=0.5)$ and b) $\Delta V^{\prime} \mathrm{I} / \Delta P \mathrm{a}_{1}, \mathrm{CO}_{2}=2.36 \times \Delta \mathrm{CBV} / \Delta P \mathrm{a}, \mathrm{CO}_{2}+3.99$ $(\mathrm{r}=0.38 ; \mathrm{p}<0.05) . V^{\prime} \mathrm{I}$ : inspired minute ventilation $\left(\mathrm{L} \cdot \mathrm{min}^{-1}\right)$; CBV: cerebral blood volume $\left(\mathrm{mL} \cdot 100 \mathrm{~g}^{-1}\right)$.

correlated. There was no correlation between absolute values of $\mathrm{CBV}$ and $\mathrm{HR}$ in normocapnic $(\mathrm{r}=0.1)$ and hypercapnic COPD patients $(\mathrm{r}=0.2)$ and controls $(\mathrm{r}<0.1)$.

\section{Discussion}

Cerebrovascular responses were studied and correlated with ventilatory reactivity in healthy subjects and both normo- and hypercapnic COPD patients. Acute hypercapnia gave rise to significant changes of CBV and ventilatory ( $V^{\prime} I$ and $\left.P 0.1\right)$ outcome parameters in all investigated subjects. Healthy subjects showed the highest CBV- and $V^{\prime}$ I-responsiveness, whereas hypercapnic COPD patients showed the poorest responsiveness among the three groups. A wide inter-individual variability of cerebrovascular and ventilatory reactivity to acute changes in $P$ a, $\mathrm{CO}_{2}$ was found between the investigated subjects. However, the present study showed a tendency of high cerebrovascular responses being accompanied by high 

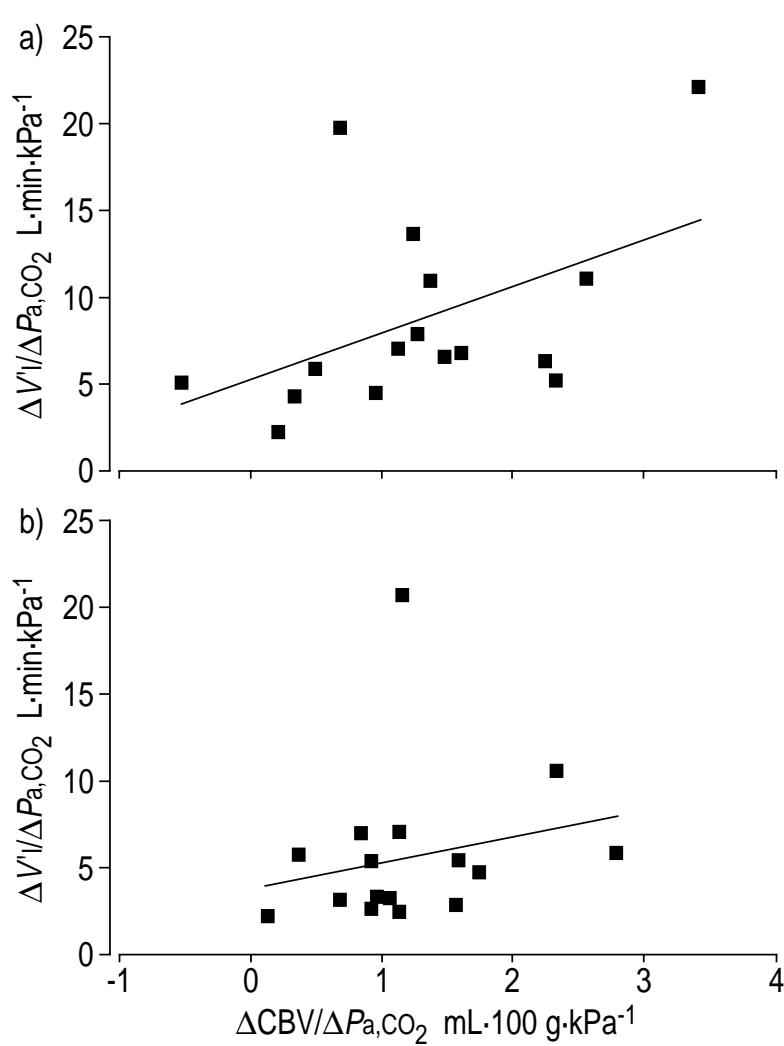

Fig. 4. - Correlation between ventilatory and cerebrovascular carbon dioxide $\left(\mathrm{CO}_{2}\right)$-responsiveness in normocapnic and chronic hypercapnic chronic obstructive pulmonary disease (COPD) patients. The relationship between a) the individual ventilatory/ $\mathrm{CO}_{2}$ tension in arterial blood $\left(\Delta V^{\prime} \mathrm{I} / \Delta P \mathrm{a}_{1}, \mathrm{CO}_{2}\right)$ and cerebrovascular

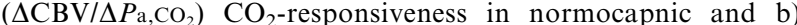
chronic hypercapnic patients. The regression equation, describing the inter-individual relationship between a) $\Delta V^{\prime} \mathrm{I} / \Delta P \mathrm{a}, \mathrm{CO}_{2}$ and $\Delta \mathrm{CBV} / \Delta P \mathrm{a}_{1} \mathrm{CO}_{2}$ is $\Delta V^{\prime} \mathrm{I} / \Delta P \mathrm{a}, \mathrm{CO}_{2}=2.66 \times \Delta \mathrm{CBV} / \Delta P \mathrm{a}, \mathrm{CO}_{2}+5.22$ $(\mathrm{r}=0.20 ; \mathrm{p}=0.47)$ and b) $\Delta V^{\prime} \mathrm{I} / \Delta P \mathrm{a}_{1} \mathrm{CO}_{2}=1.43 \times \Delta \mathrm{CBV} / \Delta P \mathrm{a}_{1} \mathrm{CO}_{2}+$ $3.79(\mathrm{r}=0.21 ; \mathrm{p}=0.41)$. $V^{\prime} \mathrm{I}$ : inspired ventilation $\left(\mathrm{L} \cdot \mathrm{min}^{-1}\right) ; \mathrm{CBV}$ : cerebral blood volume $\left(\mathrm{mL} \cdot 100 \mathrm{~g}^{-1}\right)$

ventilatory repsonses to $\mathrm{CO}_{2}$, thus refuting the hypothesis of an inverse relationship between $\triangle \mathrm{CBV} / \triangle P \mathrm{a}, \mathrm{CO}_{2}$ and $\Delta V^{\prime} \mathrm{I} / \Delta P \mathrm{a}, \mathrm{CO}_{2}$ in COPD patients.

\section{Ventilation and ventilatory responses}

Ventilatory responsiveness to $\mathrm{CO}_{2}$ were highest in healthy subjects and lowest in hypercapnic COPD patients. The results are in line with those of others [1, $8,16]$, although the present study measured higher absolute values of responsiveness. The latter can be explained by various causes. Firstly, the present study used $P \mathrm{a}, \mathrm{CO}_{2}$ instead of $P \mathrm{ET}, \mathrm{CO}_{2}$ as an independent variable. Secondly, the (significantly) increased value of $\mathrm{Pa}, \mathrm{O}_{2}$ during hypercapnic challenge may have resulted in an overestimated value of ventilatory $\mathrm{CO}_{2}$ responses, as previous reports found a reduced $\mathrm{CO}_{2}$ sensitivity during hyperoxia in healthy subjects [17]. Thirdly, chronic hypercapnic patients were exposed to chronic hypoxaemia (mean $\mathrm{Pa}_{\mathrm{a}} \mathrm{O}_{2}$ value $8.31 \mathrm{kPa}$ ). Superimposed desaturation changes to obtain absolute CBV values may have led to greater values of ventilation under both baseline conditions and during hypercapnic challenge, possibly leading to higher values of ventilatory slopes. Finally, all COPD patients have inhaled $\beta_{2}$-adrenergic agonists, resulting in additional increases in ventilatory responses to hypercapnia, presumably by central chemoreceptor stimulation [18].

The sex ratio in healthy controls' and patients' groups is different. As all the subjects investigated were postmenopausal, this study is not predominantly biased by sex.

To ascertain whether and to what extent the reduced ventilatory response to a hypercapnic stimulus in COPD patients depends on a blunted chemoresponsiveness of central origin or to mechanical impairment, SCANo et al. [8] measured rebreathing $\mathrm{CO}_{2}$ responses in normocapnic and hypercapnic COPD patients with similar degrees of airway obstruction and hyperinflation. Their study population was comparable to the present investigated group on pulmonary mechanics and arterial blood gas parameters. In contrast to GELB et al. [16] and the present study, they found a lower $P_{0.1}$ responsiveness $\left(\mathrm{cmH}_{2} \mathrm{O} \cdot \mathrm{kPa}^{-1}\right)$ in hypercapnics $(1.08 \pm 0.43)$ relative to normocapnics $(2.72 \pm 2.08)$ and healthy controls $(2.57 \pm 0.49)$. Conversely, when the normalization of $P 0.1$ for individual differences in muscle strength was performed by expressing $P_{0.1}$ as a percentage of MIP [15], a significant difference between the two groups did not occur, which is in line with the present results.

\section{Cerebral blood volume and cerebrovascular responses}

Cerebrovascular responsiveness was expressed as a change of CBV over a change in $\mathrm{Pa}, \mathrm{CO}_{2}$. It is important to consider the advantages of measurements of $\mathrm{CBV}$ over $\mathrm{CBF}$ measurements. Firstly, there is a close relationship $(r=0.9)$ between $\mathrm{CBV}$ and CBF that has been extensively investigated [19]. Secondly, the use of $\mathrm{CBV}$ instead of $\mathrm{CBF}$ eliminates the problems related to the mean cerebral transit time [20]. Finally, nearinfrared absorption changes reflect changes in the oxygenation of blood in the microvasculature, and thus the CBV of the brain tissue [21]. Changes of CBV also reflects capillary recruitment, which are considered a better reflection of cerebrovascular responses than $\mathrm{CBF}$ responses to acid-base stimuli [20].

CBV was measured in the frontal cortex, which may not react in the same way as the brain-stem region, where the central chemoreceptors are located [22]. However, Hida et al. [23] used transcranial Doppler to determine changes in blood flow velocity and could not find any differences in $\mathrm{CO}_{2}$ responses between the brain-stem artery and the middle-cerebral artery using transcranial Doppler. The latter paper would support the present measurements of frontal-lobe vasoresponsiveness to be representative of overall CBV changes. However, since there is no general agreement on cerebrovascular $\mathrm{CO}_{2}$-responsiveness, one has to be cautious to draw this conclusion.

Prior to this study, the reproducibility of CBV measurements during resting conditions using NIRS 
was evaluated; an intra-individual coefficient of variation of $\pm 10 \%$ was found [24]. These results are in agreement with others [25]. CBV values of the present study during normocapnia (range $1.60-4.30 \mathrm{~mL} \cdot 100 \mathrm{~g}^{-1}$ ) are consistent with other studies using NIRS: $2.85 \pm$ $0.97 \mathrm{~mL} \cdot 100 \mathrm{~g}^{-1}$ [25].

Absolute values of CBV were lower in both COPD groups, relative to healthy subjects. Increased age [26], haematocrit [27] and HR may lower $\mathrm{CBF}$ and, therefore, CBV. HR was significantly increased in both COPD groups. HR responses primarily test the parasympathetic system. STEWART et al. [28] showed a parasympathetic autonomic dysfunction in 93\% (28 out of 30) of severe hypoxaemic, hypercapnic COPD patients and in 65\% (39 out of 60) of moderately to severely hypoxic, normocapnic COPD patients. Only $18 \%$ (four out of 22) of the control group had evidence of an age-related autonomic dysfunction. However, a correlation between absolute values of CBV and HR was not found in the present study. Additionally, no correlation was found between absolute values of CBV and age.

Medication, like theophyllines and systemic corticosteroids, may reduce CBV [29, 30]. Theophylline was chronically used by nine of $16(56 \%)$ normocapnic and 11 of 17 (64\%) hypercapnic patients, which may have contributed to the low CBV in both COPD groups. Systemic corticosteroids were used in four out of 16 normocapnic and four out of 17 hypercapnic patients. To assess the effect of medical intervention, average CBV was recalculated after subdividing both COPD groups in users and nonusers of theophyllines and/or oral corticosteroids. In contrast to others [29, 30], CBV was slightly, but not significantly higher in the group of theophylline users, relative to the nonusers in both COPD groups. In addition, CBV values measured in corticosteroid-users and nonusers were not different. Both the small size of the subgroups and the high variation of CBV values among the subjects may mask the well-documented effects of theophyllines. Intravenous salbutamol $\left(1 \mu \mathrm{g} \cdot \mathrm{kg}^{-1}\right)$ leads to an increased $\mathrm{CBV}$ in rats [31]. Since the present study showed a low CBV in all COPD patients, it is unlikely that the inhaled salbutamol $(\leqslant 400 \mu \mathrm{g})$ of the patients affected the $\mathrm{CBV}$ values substantially.

MABP was relatively higher in all COPD patients and remained unchanged during hypercapnia. Although their MABP values fell well within the range of autoregulation, pressure-dependent sensors may dominate flow-dependent sensors in the cerebral circulation during chronic elevated blood pressure, leading to a lowering of CBF and CBV. This might partly explain a blunted cerebrovascular responsiveness in both COPD groups, compared to healthy subjects.

There are only a few studies describing CBV reactivity in adults using NIRS. GUPTA et al. [32] used the same method as the present study to calculate CBV and found a higher mean CBV of $5.38 \mathrm{~mL} \cdot 100 \mathrm{~g}^{-1}$ and a lower CBV reactivity of $1.25 \mathrm{~mL} \cdot 100 \mathrm{~g}^{-1} \cdot \mathrm{kPa}^{-1}$, in young adults. However, they induced deeper desaturations $(\Delta 10-15 \%$, instead of $\sim 5 \%)$, assumed equal $\mathrm{Hb}$ values for each individual and used the fractional concentration of $\mathrm{CO}_{2}$ in expired gas to correlate with CBV. As they suggested, a deeper desaturation possibly gives rise to concomittant hypoxic vasodilation and thereby, a higher CBV and different $\mathrm{CBV}$ reactivity. Other studies applied the same "O $\mathrm{O}_{2}$-desaturation-method" in neonates [33], or used $\mathrm{O}_{2} \mathrm{Hb}$ derived reactivity values, and are therefore not comparable with this study [34].

\section{Conclusions}

Normocapnic and chronic hypercapnic COPD patients had lower absolute values of CBV relative to healthy subjects; autonomic dysfunction was suggested as a possible reason for this difference. There was a poor, but positive correlation between ventilatory and cerebrovascular $\mathrm{CO}_{2}$ responsiveness $\left(\Delta \mathrm{CBV} / \Delta P \mathrm{a}, \mathrm{CO}_{2}\right.$ and $\left.\Delta V^{\prime} \mathrm{I} / \Delta P \mathrm{a}, \mathrm{CO}_{2}\right)$ in COPD patients and healthy subjects, thus refuting the hypothesis concerning an inverse relationship between cerebrovascular and ventilatory responses to $\mathrm{Pa}, \mathrm{CO}_{2}$.

As compared to healthy subjects, both chronic obstructive pulmonary disease groups showed lower ventilatory as well as cerebrovascular carbon dioxideresponses, with significantly lower responses in the chronic hypercapnic group. Since similar mouth occlusion pressure reactivity was measured in both chronic obstructive pulmonary disease groups and cerebral blood volume- and inspired minute ventilation-reactivity were not significantly different, the present study was not able to elucidate why some patients with chronic obstructive pulmonary disease become hypercapnic, whereas others with the same degree of airway obstruction remain normocapnic.

\section{References}

1. Fahey PJ, Hyde RW. "Won't breathe" vs "can't breathe". Detection of depressed ventilatory drive in patients with obstructive pulmonary disease. Chest 1983; 84: 19-25.

2. Bruce EN, Cherniack NS. Central chemoreceptors. J Appl Physiol 1987; 62: 389-402.

3. Kety SS, Schmidt CF. The effects of altered arterial tensions of carbon dioxide and oxygen on cerebral blood flow and cerebral oxygen consumption of normal young men. J Clin Invest 1947; 27: 484-492.

4. Berkenbosch A, De Goede J, Olievier CN, et al. Influence of the CSF bicarbonate concentration on the ventilatory response to $\mathrm{CO}_{2}$ in relation to the location of the central chemoreceptors. Respir Physiol 1978; 35: 215-236.

5. Feihl F, Perret C. Permissive hypercapnia. How permissive should we be? Am J Respir Crit Care Med 1994; 150: 1722 - 1737

6. Levasseur JE, Wei EP, Kontos HA, Patterson JLJ. Responses of pial arterioles after prolonged hypercapnia and hypoxia in the awake rabbit. $J$ Appl Physiol 1979; 46: 89-95.

7. Montes de Oca M, Celli BR. Mouth occlusion pressure, $\mathrm{CO}_{2}$ response and hypercapnia in severe chronic obstructive pulmonary disease. Eur Respir $J$ 1998; 12: $666-671$.

8. Scano G, Spinelli A, Duranti R, et al. Carbon dioxide 
responsiveness in COPD patients with and without chronic hypercapnia. Eur Respir J 1995; 8: 78 -85.

9. Pontén U, Siesjö BK. Gradients of $\mathrm{CO}_{2}$ tension in the brain. Acta Physiol Scand 1966; 67: 129-140.

10. Jobsis FF. Noninvasive, infrared monitoring of cerebral and myocardial oxygen sufficiency and circulatory parameters. Science 1977; 198: 1264-1267.

11. Hebden JC, Delpy DT. Diagnostic imaging with light. Br J Radiol 1997; 70: 5206-5214.

12. Harris DN, Cowans FM, Wertheim DA, Hamid S. NIRS in adults-effects of increasing optode separation. Adv Exp Med Biol 1994; 345: 837-840.

13. Elwell CE, Cope M, Edwards AD, Wyatt JS, Delpy DT, Reynolds EO. Quantification of adult cerebral hemodynamics by near-infrared spectroscopy. $J$ Appl Physiol 1994; 77: 2753-2760.

14. Whitelaw WA, Derenne JP, Milic EJ. Occlusion pressure as a measure of respiratory center output in conscious man. Respir Physiol 1975; 23: 181-199.

15. Gorini M, Spinelli A, Ginanni R, Duranti R, Gigliotti F, Scano G. Neural respiratory drive and neuromuscular coupling in patients with chronic obstructive pulmonary disease (COPD). Chest 1990; 98: 11791186.

16. Gelb AF, Klein E, Schiffman P, Lugliani R, Aronstam $P$. Ventilatory response and drive in acute and chronic obstructive pulmonary disease. Am Rev Respir Dis 1977; 116: 9-16.

17. Dahan A, DeGoede J, Berkenbosch A, Olievier IC. The influence of oxygen on the ventilatory response to carbon dioxide in man. $J$ Physiol 1990; 428: 485-499.

18. Suzuki S, Watanuki Y, Yoshiike Y, Okubo T. Effects of fenoterol on ventilatory response to hypercapnia and hypoxia in patients with chronic obstructive pulmonary disease. Thorax 1997; 52: $125-129$.

19. van Zijl PC, Eleff SM, Ulatowski JA, et al. Quantitative assessment of blood flow, blood volume and blood oxygenation effects in functional magnetic resonance imaging. Nat Med 1998; 4: 159-167.

20. Shockley RP, LaManna JC. Determination of rat cerebral cortical blood volume changes by capillary mean transit time analysis during hypoxia, hypercapnia and hyperventilation. Brain Res 1988; 454: 170178.

21. Mancini DM, Bolinger L, Li H, Kendrick K, Chance $\mathrm{B}$, Wilson JR. Validation of near-infrared spectroscopy in humans. J Appl Physiol 1994; 77: 2740-2747.

22. Ito H, Yokoyama I, Iida $\mathrm{H}$, et al. Regional differences in cerebral vascular response to $\mathrm{Pa}, \mathrm{CO}_{2}$ changes in humans measured by positron emission tomography. J Cereb Blood Flow Metab 2000; 20: $1264-1270$.
23. Hida W, Kikuchi Y, Okabe S, Miki H, Kurosawa H, Shirato $\mathrm{K} . \mathrm{CO}_{2}$ response for the brain stem artery blood flow velocity in man. Respir Physiol 1996; 104: $71-75$.

24. Van de Ven MJT, Colier WNJM, van der Sluijs MC, Walraven D, Oeseburg B, Folgering H. Can cerebral blood volume be measured reproducibly with an improved near infrared spectroscopy system? J Cereb Blood Flow Metab 2001; (in press).

25. Elwell CE, Cope M, Edwards AD, Wyatt JS, Reynolds EO, Delpy DT. Measurement of cerebral blood flow in adult humans using near infrared spectroscopy-methodology and possible errors. $A d v$ Exp Med Biol 1992; 317: 235-245.

26. Dorfler P, Puls I, Schliesser M, Maurer M, Becker G. Measurement of cerebral blood flow volume by extracranial sonography. J Cereb Blood Flow Metab 2000; 20: 269-271.

27. York EL, Jones RL, Menon D, Sproule BJ. Effects of secondary polycythemia on cerebral blood flow in chronic obstructive pulmonary disease. Am Rev Respir Dis 1980; 121: 813-818.

28. Stewart AG, Waterhouse JC, Howard P. Cardiovascular autonomic nerve function in patients with hypoxaemic chronic obstructive pulmonary disease. Eur Respir J 1991; 4: $1207-1214$.

29. Bowton DL, Stump DA, Anderson R. Effect of chronic theophylline therapy on brain blood flow and function in adult asthmatics. Am J Respir Crit Care Med 1994; 150: $1002-1005$.

30. Schraa JC, Dirks JF. The influence of corticosteroids and theophylline on cerebral function. A review. Chest 1982; 82: $181-185$.

31. Buchweitz ME, Weiss HR. Effect of salbutamol on regional cerebral oxygen consumption, flow and capillary and arteriolar perfusion. Neurol Res 1990; 12: $169-175$.

32. Gupta AK, Menon DK, Czosnyka M, Smielewski P, Kirkpatrick PJ, Jones JG. Non-invasive measurement of cerebral blood volume in volunteers [published erratum appears in $\mathrm{Br} J$ Anaesth 1997; 78: 486]. $\mathrm{Br}$ J Anaesth 1997; 78: 39-43.

33. Brun NC, Greisen G. Cerebrovascular responses to carbon dioxide as detected by near-infrared spectrophotometry: comparison of three different measures. Pediatr Res 1994; 36: 20 - 24.

34. Smielewski P, Czosnyka M, Pickard JD, Kirkpatrick P. Clinical evaluation of near-infrared spectroscopy for testing cerebrovascular reactivity in patients with carotid artery disease. Stroke 1997; 28: $331-338$. 